\title{
Invasive alien clonal plants are competitively superior over co-occurring native clonal plants
}

\author{
Yong-Jian Wang ${ }^{\mathrm{a}}$, Duo Chen ${ }^{\mathrm{a}}$, Rong Yan ${ }^{\mathrm{a}}$, Fei-Hai Yu ${ }^{\mathrm{b}, *}$, Mark van Kleunen ${ }^{\mathrm{c}}$ \\ ${ }^{\mathrm{a}}$ Hubei Engineering Technology Research Center for Forestry Information / College of Horticulture \& Forestry Sciences, Huazhong Agricultural University, Wuhan 430070, \\ China \\ ${ }^{\mathrm{b}}$ Institute of Wetland Ecology \& Clone Ecology / Zhejiang Provincial Key Laboratory of Plant Evolutionary Ecology and Conservation, Taizhou University, Taizhou 318000, \\ China \\ ${ }^{\mathrm{c}}$ Ecology, Department of Biology, University of Konstanz, Universitätsstrasse 10, D-78457 Konstanz, Germany
}

\begin{abstract}
A B S T R A C T
Alien plant invasions are a major component of global change, and can severely threaten local floras and global biodiversity. A striking pattern of invasive floras is that many of the world's worst invasive plants are clonal species. However, it is still unclear whether invasive clonal plant species are in general competitively superior over native clonal plant species and whether this pattern can be affected by environmental conditions. To test whether nitrogen $(\mathrm{N})$ availability and suppression of enemies can alter the competitive outcome between invasive alien and resident native clonal plants, we selected five pairs of invasive alien and co-occurring native clonal plant species in China. We grew them both in monocultures (i.e. with intraspecific competition) and in two-species mixtures (i.e. with interspecific competition) with or without $\mathrm{N}$ addition, and with or without suppression of enemies (using insecticide and fungicide application). Overall, invasive alien clonal plants produced significantly more biomass than native clonal plants, and took more advantage of $\mathrm{N}$ addition. Invasive clonal plants tended to grow better with interspecific than with intraspecific competition, whereas the reverse was true for native clonal plants. This species-origin-by-competition interaction, however, was weaker with than without $\mathrm{N}$ addition. Without enemy suppression, native clonal plants experienced more leaf damage than invasive aliens when they grew in interspecific competition with each other, but only in the absence of $\mathrm{N}$ addition. Nevertheless, enemy suppression benefited growth of invasive alien and native clonal plants to similar degrees. Our results show that already under strongly N-limited conditions, invasive clonal plants in China are competitively superior over natives, and that this competitive superiority of invasive clonal plants becomes even stronger after $\mathrm{N}$ addition. This implies that the ongoing eutrophication of many habitats is likely to further

stimulate invasions by clonal plants.
\end{abstract}

Keywords:

Clonal growth

Competition

Enemy release hypothesis

Exotic plants

Invasiveness

Multi-species comparison

\section{Introduction}

Thousands of alien plant species, including those that can propagate clonally (i.e. alien clonal plant species), have established populations in the wild after intentional or unintentional introduction by human agency (van Kleunen et al., 2015v; Pyšek et al., 2017). Some of those spread rapidly and have become invasive (Richardson et al., 2000). Many invasive species also can become very dominant (Catford et al., 2016), although they may show similar dominance in their native ranges (Firn et al., 2011). Nevertheless, it is generally assumed that invasive alien plants are competitively superior over most native resident plants (Callaway and Ridenour, 2004; Funk and Vitousek, 2007; Whitney and Gabler, 2008; Seabloom et al., 2015; Zheng et al., 2015).
Support for this hypothesis comes from the comparison of traits between invasive alien and native plants (Ordonez et al., 2010; Godoy et al., 2011; Liu et al., 2017). For instance, invasive alien plants in general have higher values for growth rate, size and fitness measures than native plants (van Kleunen et al., 2010v). Recent studies focusing on clonal species have shown that invasive alien clonal plants also have better growth performance than non-invasive alien (Keser et al., 2014) or native clonal plants (Wang et al., 2017; Chen et al., 2019; Liu et al., 2019). Moreover, a recent meta-analysis of published experimental studies on competition revealed that invasive alien plants usually have stronger competitive effects on natives than vice versa (Kuebbing and Nuñez, 2016). However, few studies have tested for competitive interactions among multiple invasive and native species within one

\footnotetext{
* Corresponding author at: Institute of Wetland Ecology \& Clone Ecology, Taizhou University, Taizhou 318000, China.

E-mail address: feihaiyu@126.com (F.-H. Yu).
} 
experiment, especially for clonal plant species. Moreover, there is still limited understanding of the extent to which competition between invasive and native clonal species depends on environmental change.

Environmental conditions are likely to modulate the outcome of competition between alien and native plants, and thus whether a native community can be invaded by alien plant species or not (Alpert et al., 2000; Rao and Allen, 2010; Li et al., 2014). A major global environmental change component is the anthropogenic increase in nitrogen $(\mathrm{N})$ availability through aerial deposition (Galloway et al., 2008) and agricultural application of fertilizers (Li et al., 2014; Song and Yu, 2015). When $\mathrm{N}$ is limited, an increase in $\mathrm{N}$ availability stimulates the growth of plants (Schumacher et al., 2009; Littschwager et al., 2010; Liu et al., 2019). Studies have shown that increasing $\mathrm{N}$ availability could benefit invasive alien plants more than native plants in competition-free environments (Schumacher et al., 2009; Littschwager et al., 2010; Liu and van Kleunen, 2017). This suggests that invasive plants can take up and utilize $\mathrm{N}$ more effectively than most natives at high $\mathrm{N}$ supply, at least when grown without competition (Schumacher et al., 2009; Littschwager et al., 2010).

Studies on native plants have shown that $\mathrm{N}$ addition can intensify competitive interactions between native plants and accelerate the replacement of weaker species by stronger native competitors (e.g. Aerts and Berendse, 1988; van Mierlo et al., 2000v; Hautier et al., 2009). However, less is known about whether increasing $\mathrm{N}$ deposition alters the outcome of competition between invasive alien and native plants (Rickey and Anderson, 2004; Parepa et al., 2013; Huang et al., 2016). Some previous studies showed that enhanced growth of invasive species after $\mathrm{N}$ addition suppressed the growth of the native species (Huang et al., 2016), but that others did not find this (Rickey and Anderson, 2004). These studies, however, focused on few species, which makes it difficult to generalize. Therefore, we need multi-species studies (van Kleunen et al., 2014v) to find out whether and how N availability generally alters the outcome of competition between invasive alien and co-occurring native plants, especially for clonal ones.

Another important environmental factor that may affect the outcome of competition between invasive and native plants is the presence of enemies, such as herbivores and fungal pathogens (Maron and Vilà, 2001; Agrawal and Kotanen, 2003; Agrawal et al., 2005; Heard and Sax, 2013; Beckmann et al., 2016). Changes in plant-enemy interactions are the basis for many hypotheses that provide mechanistic explanations for plant invasion success (Elton, 1958; Blossey and Nötzold, 1995; Keane and Crawley, 2002; Müller-Schärer et al., 2004; Catford et al., 2009). However, although some studies tested for effects of enemy release on invasive species sown or planted in native plant communities (Strauss et al., 2009; Korell et al., 2016a, 2016b; Müller et al., 2016), it is unclear whether release from enemies alters the outcome of competition between invasive alien and native clonal plants. It is difficult to manipulate enemy release for only one of the competing species. However, if invasive alien clonal plants are already released from enemies, as predicted by the enemy-release hypothesis, experimental suppression of enemies should mainly release the native clonal plant species from enemies, and thus boost their competitive ability.

To test whether and how $\mathrm{N}$ addition and enemies affect competition between invasive and native plants, we grew five pairs of invasive alien and co-occurring common native clonal plant species in China both in monocultures and in two-species mixtures with or without $\mathrm{N}$ addition and with or without enemy suppression. We focused on clonal plants, because they usually are, due to their vegetative spread, strong competitors, and many highly invasive alien species - including some of the world's worst invasive alien species - are clonal (Pyšek, 1997; Lowe et al., 2000; Liu et al., 2006; Song et al., 2013; Wang et al., 2017; Chen et al., 2019). Specifically, we addressed the following questions: (1) Do invasive alien clonal plants show competitive superiority over co-occurring native clonal plants in terms of biomass production? (2) Does N addition affect the outcome of competition between invasive alien and native clonal plants? (3) Does enemy suppression affect the outcome of competition between invasive alien and native clonal plants?

\section{Materials and methods}

\subsection{Study species and pre-cultivation}

We used five pairs of clonal herbaceous plant species; four pairs consist of stoloniferous plants and one pair consists of rhizomatous plants (Table A1). Within each pair, one species is an invasive alien in China (Wan et al., 2012; Ma, 2014; Ma and Li, 2018), and the other is a common native in China and co-occurs with the invasive alien species in the field. If possible, we chose species that belong to the same family (or genus) to account for phylogenetic relatedness of the two species within a pair ( 3 of the 5 pairs consist of congeneric species; Table A1).

All plants used had been collected from field sites in the Hubei or Guangdong provinces (China) in 2014. For each species, we had collected more than 100 ramets from five locations $>500 \mathrm{~m}$ apart to increase the likelihood of sampling ramets from different genotypes (genets). The collected ramets were then vegetatively propagated in a greenhouse at Huazhong Agricultural University in Wuhan, Hubei Province, China. In 2016, we selected 60 ramets of similar sizes for each species, and used them for the experiment described below. Each ramet had three leaves and several roots.

\subsection{Experimental design}

For each of the 10 species, the 60 ramets were randomly assigned to a factorial design of two levels of competition (intra- vs. interspecific), two levels of $\mathrm{N}$ addition (with vs. without) and two levels of enemy suppression (with vs. without). On 7 June 2016, we planted the ramets in pots (dimensions: $24 \mathrm{~cm} \times 24 \mathrm{~cm} \times 20 \mathrm{~cm}$ ) filled with an 1:1 (v:v) mixture of river sand and soil collected from Shizishan Mountain in Wuhan, Hubei Province, China. The soil mixture contained a total $\mathrm{N}$ of $0.25 \pm 0.03 \mathrm{~g} \mathrm{~kg}^{-1}$, a total $\mathrm{P}$ of $0.36 \pm 0.04 \mathrm{~g} \mathrm{~kg}^{-1}$ and a total $\mathrm{K}$ of $18.24 \pm 1.22 \mathrm{~g} \mathrm{~kg}^{-1}($ mean $\pm \mathrm{SE}, \mathrm{n}=10)$. The pots were placed in a plastic greenhouse at Huazhong Agricultural University, Wuhan, China. The greenhouse was open on the sides to allow entrance of insect herbivores and pollinators. However, a fence prevented access to larger animals (e.g. birds and mammals). After two weeks for recovery of the plants from transplanting (on 21 June 2016), we started the experimental treatments.

For the intraspecific competition treatment, we grew two ramets of the same species in a pot. For the interspecific competition treatment, we grew one ramet of each of the two species within a pair in a pot. The two ramets in each pot were planted c. $8 \mathrm{~cm}$ apart. For the high-N treatment, we added $200 \mathrm{ml} \mathrm{N}$-fertilizer solution (containing $0.110 \mathrm{~g}$ $\mathrm{NH}_{4} \mathrm{NO}_{3}$ corresponding to $0.0385 \mathrm{~g} \mathrm{~N}$ ) to a pot once a week, and for the low-N treatment, we added $200 \mathrm{ml}$ water as a control. For the treatment with enemy suppression, we sprayed the aboveground parts of the plants with a broad-spectrum insecticide (concentration: $2 \mathrm{ml} \mathrm{L}^{-1}$; main ingredients: chlorpyrifos and fenvalerate; The Dow Chemical Company, Midland, USA) and also added to the soil a solution consisting of a mixture of the same broad-spectrum insecticide (concentration: $2 \mathrm{ml} \mathrm{L}^{-1}$ ) and two broad-spectrum fungicides with the main ingredients benzimidazole $\left(1.5 \mathrm{~g} \mathrm{~L}^{-1}\right.$; Nufarm Limited, Contatti, Italy) and copper oxychloride $\left(1.5 \mathrm{~g} \mathrm{~L}^{-1}\right.$; Dupont agricultural Products, Washington DE, United States) every other week (Zheng et al., 2015). For the control treatment without enemy suppression, we sprayed the plants with water and also added corresponding amounts of water to the soil.

During the experiment, the total amount of $\mathrm{N}$ added in the N-addition treatment corresponded to $8 \mathrm{~g} \mathrm{~N} \mathrm{~m}^{-2}$ year $^{-1}$, which is within the range of the current level of atmospheric $\mathrm{N}$ deposition in China (Liu et al., 2013; Xu et al., 2015). We added $200 \mathrm{ml}$ of water to each pot every one to three days depending on the weather conditions, and thus on how fast the soil dried out. During the experiment, mean soil water 
content was $27.68 \pm 2.53 \%$ (mean \pm SE), as measured once a day in ten randomly selected pots by a soil-moisture meter (TZS-II, HEB Biotechnology Co., Xi'an, China). The mean temperature in the greenhouse was $29.4^{\circ} \mathrm{C}$ and the mean relative humidity was $79.1 \%$ (measured with an Amprobe TR300, Amprobe, Everett, WA, USA). Light intensity in the greenhouse was $70 \%$ of that outside. The pots were randomly allocated to positions in the greenhouse and were randomly rearranged every two weeks to minimize the potential effect of heterogeneity in micro-environmental conditions. There were five replicate pots for each treatment combination and species pair, resulting in a total of 300 pots (5 species pairs $\times 3$ species combinations [i.e. 2 monocultures and 1 mixture $] \times 2 \mathrm{~N}$ treatments $\times 2$ enemy suppression treatments $\times 5$ replicates).

\subsection{Measurements}

The experiment was terminated on 12 September 2016, 12 weeks after the start of the treatments, when the growth of most species had slown down. We first counted the ramets of each of the two plants in each pot as estimates of vegetative reproduction. Then we estimated visually for each leaf the proportion of area removed by herbivores, and calculated the average proportion of leaf area removed per plant (Agrawal and Kotanen, 2003; Agrawal et al., 2005). After these nondestructive measurements, we harvested the two plants in each pot separately. Each plant was separated into leaves, roots and stolons (for stoloniferous plants) or rhizomes (for rhizomatous plants). For simplicity, we refer hereafter to both stolons and rhizomes as clonal growth organs. These plant parts were dried in an oven at $60^{\circ} \mathrm{C}$ for $72 \mathrm{~h}$, and then weighed to obtain dry mass.

\subsection{Statistical analysis}

For each species in a pot, we first calculated each of the growth measures (total mass, leaf mass, clonal growth organ mass, root mass and number of ramets) per individual plant (i.e. per initially planted ramet) by dividing each growth measure by two in monocultures and by one in mixtures. As a measure of allocation of biomass to roots, we calculated the root weight ratio as root mass divided by total mass of the plant. We then analyzed the effects of the treatments on the different growth measures and on root weight ratio using linear mixed models with the lme function in the R package 'nlme' (R Development Core Team, 2012; Pinheiro et al., 2015). In these models, species origin (invasive alien vs. native), $\mathrm{N}$ addition (with vs. without), enemy suppression (with vs. without), competition type (intraspecific vs. interspecific) and their interactions were treated as fixed terms. To account for non-independence of species in a pair and replicate plants within species, species pair and species identity (nested within species pair) were included as random terms (Zuur et al., 2009). We assessed the significance of fixed terms (i.e. species origin, $\mathrm{N}$ addition, enemy suppression and competition type) and their interactions with likelihoodratio tests (Zuur et al., 2009). In these tests, a model with the term of interest was compared to a model without the term of interest, and the calculated log-likelihood ratios, which are approximately $\chi^{2}$ distributed, were used as test statistics. We first compared models from which we had removed the four-way interaction (i.e. species origin $\times \mathrm{N}$ addition $\times$ enemy suppression $\times$ competition type) to the full model. If the fit of the two models was significantly different, according to the $\chi^{2}$ value, then there was a significant effect of the four-way interaction. Then, we removed each of the three-way or two-way interactions in turn from the model, and compared each of these models to the model with the three-way interactions but without the four-way interaction or with all two-way interactions but without all three-way interactions, respectively. By this way, we obtained the significance of each of four three-way interaction terms and each of the six two-way interaction terms. Finally, we removed the main effects of species origin, $\mathrm{N}$ addition, enemy suppression and competition type in turn, and compared these models to the model with all main effects but without any interactions to obtain the significance of each of the four main effects. Data on number of ramets were square-root transformed to meet the assumption of normality. We also analyzed leaf mass and root mass, but as they showed similar patterns to total mass and clonal growth organ mass (Table A2; Fig. A1 and A2), we did not include these results in the main manuscript.

We analyzed the data on the proportion of leaf-area removed by herbivores only for the plants without enemy suppression, as there was no clear sign of leaf-area removal on the plants with enemy suppression. Data on the proportion of removed leaf area were also analyzed using linear mixed models, with species origin, $\mathrm{N}$ addition, competition type and their interactions as fixed terms and species pair and species identity (nested within species pair) as random terms (Zuur et al., 2009). These analyses were carried out in R v.3.0.2 (R Development Core Team, 2012).

\section{Results}

\subsection{Plant performance}

The invasive alien clonal plants in our study accumulated significantly more biomass (total mass and clonal growth organ mass) than the native clonal plants, but species origin had no significant effect on number of ramets per plant (Table 1, Fig. 1). On average, $\mathrm{N}$ addition and enemy suppression (i.e. the combined application of insecticides and fungicides) significantly increased biomass and ramet production (Table 1, Fig. 1).

The positive effects of $\mathrm{N}$ addition on number of ramets were greater with interspecific than with intraspecific competition (significant $\mathrm{N}$ addition $\times$ competition type interaction in Table 1, Fig. A3). The positive effects of $\mathrm{N}$ addition on total mass and clonal growth organ mass were greater in invasive alien than in native clonal plants, as indicated by significant species origin $\times \mathrm{N}$ addition interaction (Table 1, Fig. 1B, C). Although the main effect of competition type was not significant, invasive clonal plants produced more ramets, clonal growth organ mass and total mass with interspecific than with intraspecific competition, whereas the reverse was true for native clonal plants (significant species origin $\times$ competition type interactions in Table 1, Fig. 1I-K). These differences in the effect of the competition type between invasive and native clonal plants disappeared in the $\mathrm{N}$ addition treatment (significant species origin $\times \mathrm{N}$ addition $\times$ competition type interactions in Table 1, Fig. 2A-C).

\subsection{Root allocation}

On average, root weight ratio of plants decreased in response to $\mathrm{N}$ addition (Fig. 1D) and in response to enemy suppression (Fig. 1H), but was not significantly affected by the type of competition (Table 1). The decrease in root weight ratio in response to enemy suppression, however, was only apparent for invasive clonal plants as indicated by a significant species origin $\times$ enemy suppression interaction (Table 1 , Fig. 1H).

\subsection{Herbivory damage}

With enemy suppression, plants hardly suffered from any leaf removal, whereas plants without enemy suppression had on average 13.78-35.09 \% of their leaf area removed (Fig. 3). In the subset of plants without enemy suppression, $\mathrm{N}$ addition significantly increased the proportion of leaf area removed by herbivores (Fig. 3, Table A3). On average, invasive and native clonal plants did not differ in the proportion of leaf area removed by herbivores $\left(\chi^{2}=0.18, P=0.682\right.$; Table A3). However, in the absence of $\mathrm{N}$ addition, the native clonal plants were damaged more than the invasive ones when they grew in interspecific competition with each other, whereas this was not the case 
Table 1

Results of linear mixed models for effects of species origin (invasive vs. native), N addition (without vs. with), enemy suppression (without vs. with) and competition type (intraspecific vs. interspecific) on number of ramets, total mass, clonal growth organ (CGO) mass and root weight ratio of plants.

\begin{tabular}{|c|c|c|c|c|c|c|c|c|c|}
\hline \multirow[b]{2}{*}{ Effect } & \multirow[b]{2}{*}{$\mathrm{DF}$} & \multicolumn{2}{|c|}{ No. of ramets ${ }^{1}$} & \multicolumn{2}{|c|}{ Total mass } & \multicolumn{2}{|c|}{ CGO mass } & \multicolumn{2}{|c|}{ Root weight ratio } \\
\hline & & $\chi^{2}$ & $P$ & $\chi^{2}$ & $P$ & $\chi^{2}$ & $P$ & $\chi^{2}$ & $P$ \\
\hline \multicolumn{10}{|l|}{ Fixed factor } \\
\hline Species origin $(\mathrm{O})$ & 1 & 0.44 & 0.505 & 4.63 & 0.031 & 4.09 & 0.043 & 0.40 & 0.527 \\
\hline $\mathrm{N}$ addition $(\mathrm{N})$ & 1 & 92.83 & $<0.001$ & 44.11 & $<0.001$ & 24.65 & $<0.001$ & 5.57 & 0.018 \\
\hline Enemy suppression (E) & 1 & 28.63 & $<0.001$ & 12.17 & $<0.001$ & 9.20 & 0.002 & 23.4 & 0.001 \\
\hline Competition type (C) & 1 & 0.47 & 0.493 & 1.2 & 0.273 & 0.14 & 0.707 & 0.60 & 0.440 \\
\hline $\mathrm{O} \times \mathrm{N}$ & 1 & 0.11 & 0.736 & 7.36 & 0.007 & 7.40 & 0.007 & 1.50 & 0.221 \\
\hline $\mathrm{O} \times \mathrm{E}$ & 1 & 2.37 & 0.124 & $<0.01$ & 0.939 & 0.01 & 0.923 & 6.30 & 0.012 \\
\hline $\mathrm{O} \times \mathrm{C}$ & 1 & 3.97 & 0.046 & 4.83 & 0.028 & 4.01 & 0.045 & 1.26 & 0.263 \\
\hline $\mathrm{N} \times \mathrm{E}$ & 1 & 1.65 & 0.227 & 0.98 & 0.322 & 0.86 & 0.353 & 0.95 & 0.329 \\
\hline $\mathrm{N} \times \mathrm{C}$ & 1 & 4.00 & 0.045 & 0.14 & 0.709 & 0.11 & 0.736 & 0.01 & 0.904 \\
\hline $\mathrm{E} \times \mathrm{C}$ & 1 & 1.27 & 0.260 & 0.22 & 0.638 & 0.15 & 0.696 & 0.53 & 0.467 \\
\hline $\mathrm{O} \times \mathrm{N} \times \mathrm{E}$ & 1 & 1.38 & 0.240 & 1.31 & 0.252 & 1.38 & 0.240 & 0.38 & 0.538 \\
\hline $\mathrm{O} \times \mathrm{N} \times \mathrm{C}$ & 1 & 7.82 & 0.005 & 6.33 & 0.012 & 4.11 & 0.043 & 0.64 & 0.423 \\
\hline $\mathrm{O} \times \mathrm{E} \times \mathrm{C}$ & 1 & 0.04 & 0.834 & 0.33 & 0.564 & 0.07 & 0.792 & 0.08 & 0.772 \\
\hline $\mathrm{N} \times \mathrm{E} \times \mathrm{C}$ & 1 & 1.03 & 0.310 & 0.04 & 0.838 & 0.13 & 0.721 & 0.48 & 0.490 \\
\hline $\mathrm{O} \times \mathrm{N} \times \mathrm{E} \times \mathrm{C}$ & 1 & 0.07 & 0.799 & 0.06 & 0.801 & 0.07 & 0.79 & 0.07 & 0.791 \\
\hline Random factor & $\mathrm{N}$ & $\mathrm{SD}$ & & SD & & $\mathrm{SD}$ & & SD & \\
\hline Species pair & 5 & $<0.01$ & & 1.46 & & 0.53 & & $<0.01$ & \\
\hline Species identity & 10 & 1.45 & & 1.95 & & 1.00 & & 0.06 & \\
\hline Residual & & 1.64 & & 2.71 & & 1.46 & & 0.08 & \\
\hline
\end{tabular}

${ }^{1}$ Data were square-root transformed. Values are in bold when $P<0.05$ and in italic when $0.05<P<0.1$.

when they grew under intraspecific competition or when they grew in the $\mathrm{N}$ addition treatment (Fig. 3, significant species origin $\times \mathrm{N}$ addition $\times$ competition type interaction in Table A3).

\section{Discussion}

Using five pairs of species in China, we tested for effects of competition between invasive and native clonal plants, and how these are affected by $\mathrm{N}$ addition and enemy suppression. We showed that invasive clonal species produced more biomass and capitalized more strongly on $\mathrm{N}$ addition than native clonal species. Enemy suppression had overall similar benefits for performance of invasive and native clonal plants. When invasive and native species grew in competition with each other, the invasive clonal species increased biomass production and suppressed the growth of the native clonal species, particularly in the treatment without $\mathrm{N}$ addition. These results indicate that invasive alien clonal plants are competitively superior over co-occurring native clonal plants.

\subsection{Competitive superiority of invasive alien over native clonal plants}

We found that invasive alien clonal plants overall produced more biomass than co-occurring common native clonal plants. This is consistent with findings of previous studies comparing invasive and native species (Pyšek and Richardson, 2007; González et al., 2010; Littschwager et al., 2010; van Kleunen et al., 2010v; Dawson et al., 2012b; Ordonez and Olff, 2013). More importantly, we found that the biomass production and vegetative reproduction of invasive clonal plants increased when they grew with interspecific competition compared to when they grew with intraspecific competition, whereas the reverse was true for native clonal plants. Together, these results indicate that invasive clonal plants are competitively superior over the co-occurring clonal natives. Because the native clonal plants that we selected are common in China, they are similarly successful as the invasive ones. Nevertheless, our results indicate that the invasive clonal plants in our study are competitively superior over the co-occurring clonal natives.

The ability of invasive alien plant species to rapidly take advantage of available resources could help them outperform native plants when they grow in competition (Davis et al., 2000; Richards et al., 2006; Leishman et al., 2007; Ordonez and Olff, 2013). Such differences could arise due to differences in biomass allocation to resource acquiring organs, resource-uptake efficiency of these organs and conversion of resources into biomass. Although previous studies showed differences in root and shoot allocation between invasive alien and native species (van Kleunen et al., 2010v) or between invasive and non-invasive alien species (Schlaepfer et al., 2010; Keser et al., 2014), root weight ratio did not differ between invasive and native clonal plants in our study. The differences in biomass production and interspecific competitive ability between invasive and native clonal plants are thus likely related to differences in resource-uptake efficiency or conversion of resources into biomass.

The fact that many invasive species can become very dominant and establish monocultures suggests that they are less self-limited than the non-dominant non-invasive alien or native species (Vilà and Weiner, 2004; Adler et al., 2007; Crandall and Knight, 2015). The fact that invasive clonal plants in our study grew better under interspecific than intraspecific competition, whereas the opposite was true for the native clonal plants, suggests that this is not the case for the species in our study. One possible explanation is that the invasive clonal species in our study were better able to deal with the more heterogeneous environmental conditions created by the interspecific competition treatment. This explanation is supported by the findings that invasive clonal plant species have a higher ability of clonal integration (i.e. the exchange of resources between interconnected ramets) and foraging responses (i.e. placing more biomass in resource-rich than in resource-poor patches) than non-invasive clonal plants in heterogeneous environments (Keser et al., 2014; Wang et al., 2017; Chen et al., 2019).

\subsection{Effects of $N$ availability on invasive and native clonal plants}

Not surprisingly, both invasive alien and native clonal plants produced more biomass and vegetative offspring in response to $\mathrm{N}$ addition. Moreover, and in line with the predictions of optimal resource allocation theory (Bloom et al., 1985), the species reduced the allocation to roots in response to $\mathrm{N}$ addition. The invasive clonal plants, however, benefited more in terms of biomass production from $\mathrm{N}$ addition than the native ones. These results are in line with those of previous studies 

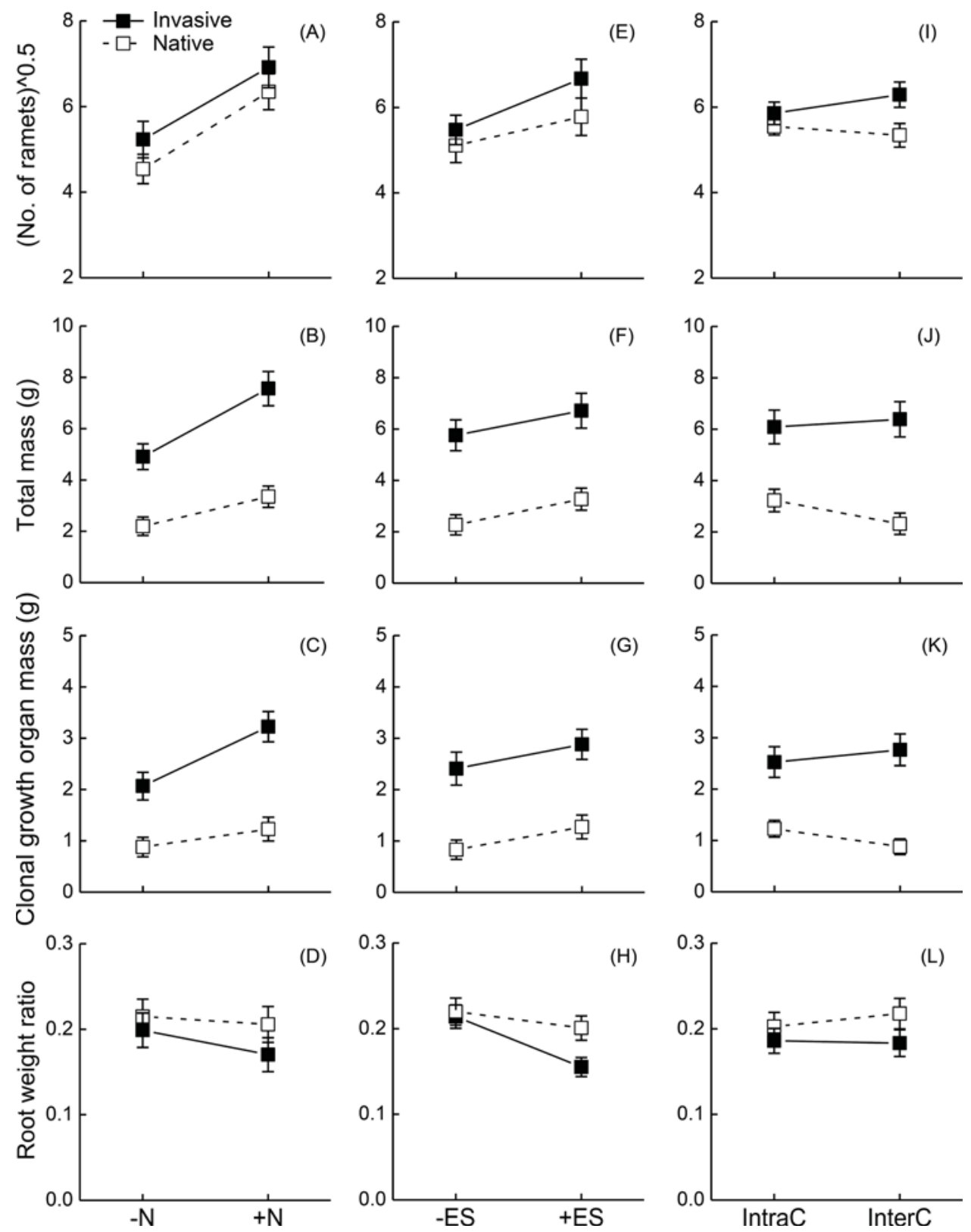

Fig. 1. Number of ramets (A, E and I), total mass (B, F and J), clonal growth organ mass (C, G and K) and root weight ratio (D, H and L) of alien invasive and native clonal plants without or with $\mathrm{N}$ addition $(-\mathrm{N}$ or $+\mathrm{N}$ ), without or with enemy suppression (-ES or + ES) and with intraspecific or interspecific competition (IntraC or InterC). Mean $\pm \mathrm{SE}$ are given. ${ }^{\wedge} 0.5$ means square-root transformed.

where invasive and native plants were grown without competition (Schumacher et al., 2009; Littschwager et al., 2010; but see Liu and van Kleunen, 2017). Similarly, several studies have shown that invasive alien plants capitalize more on additional nutrients than non-invasive alien species (Dawson et al., 2012a, b). Possibly, invasive alien plants can capitalize on the increased availability of $\mathrm{N}$ by a more effective uptake and utilization of $\mathrm{N}$ than many natives and non-invasive aliens (Schumacher et al., 2009; Littschwager et al., 2010; Heberling and Fridley, 2013). However, a recent multi-species study did not find differences in $\mathrm{N}$-acquisition ability of widely and less widely naturalized species (Liu and van Kleunen, 2019). In addition, the high ability of invasive clonal plants to share and redistribute resources within a clone through clonal integration (Song et al., 2013; Wang et al., 2017) and to position more root mass in nutrient-rich than in nutrient-poor patches (Keser et al., 2014) may allow them to take more advantage of additional nutrients.

In the absence of $\mathrm{N}$ addition, the invasive clonal plants performed better when grown with interspecific competition than when grown with intraspecific competition, whereas the opposite was true for the native clonal plants (Fig. 2). Thus, invasive plants may not only capitalize more strongly on additional nutrients (Dawson et al., 2012a, b), they may also have higher growth performance than native plant species in low resource conditions. This has also been shown in some previous studies (Funk and Vitousek, 2007; Littschwager et al., 2010; Heberling and Fridley, 2013). In the presence of $\mathrm{N}$ addition, the difference between invasive and native clonal plants in the effect of intervs. intraspecific competition became weaker or disappeared (Fig. 2). Nevertheless, the invasive clonal plants still produced much more biomass than the native clonal plants. These findings suggest that in the absence of $\mathrm{N}$ addition, the invasive clonal plants will gain in dominance when competing with the native clonal plants. In the long term, if the invasive species increase in dominance, they will experience more intraspecific competition, which will then reduce their performance (i.e. they will suffer from self-limitation). On the other hand, the 


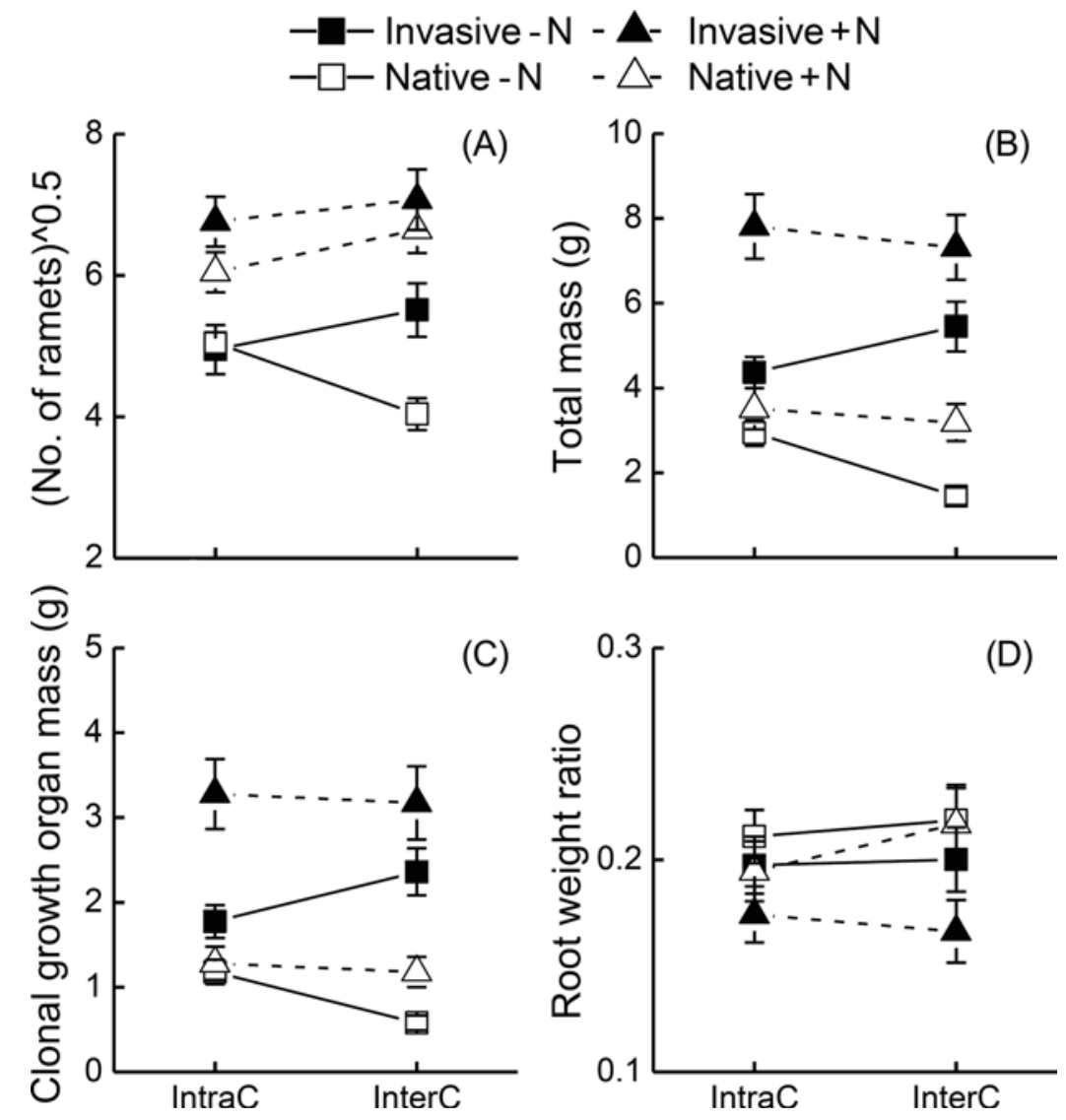

Fig. 2. Number of ramets (A), total mass (B), clonal growth organ mass (C) and root weight ratio (D) of alien invasive and native clonal plants without or with $\mathrm{N}$ addition $(-\mathrm{N}$ or $+\mathrm{N})$ and with intraspecific or interspecific competition (IntraC or InterC). Mean \pm SE are given. ${ }^{\wedge} 0.5$ means square-root transformed.

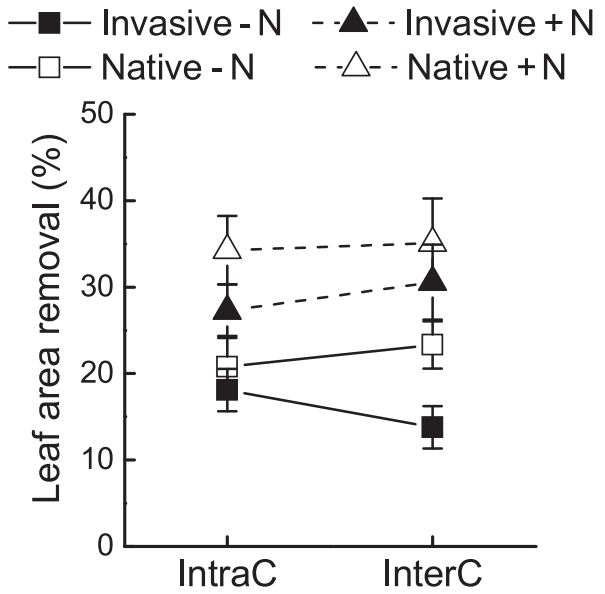

Fig. 3. The proportion of leaf area removal of invasive and native plants without enemy suppression, without or with $\mathrm{N}$ addition $(-\mathrm{N}$ or $+\mathrm{N})$ and with intraspecific or interspecific competition (IntraC or InterC). Mean $\pm \mathrm{SE}$ are given.

disappearance of the competition-type effect on performance in the presence of $\mathrm{N}$ addition implies that invasive clonal plants will become less self-limited and might become even more dominant when $\mathrm{N}$ levels continue to increase.

\subsection{Effects of enemy suppression on invasive and native clonal plants}

As expected, both the invasive and native clonal plants incurred hardly any leaf damage when enemies were suppressed with insecticides and fungicides, and this resulted in an increase in biomass production and vegetative reproduction. In the control treatment without enemy suppression, both the invasive and native clonal plants incurred leaf damage. This indicates that the invasive alien species were not entirely released from enemies, and thus that enemies provide some biotic resistance against invasive plants (Maron and Vilà, 2001; Levine et al., 2004; Kempel et al., 2013). The main enemies in our greenhouse experiment were generalist herbivores, including the larvae of Spodoptera litura and Pieris rapae (Y-J Wang, personal observation), that most likely eat both native and alien plants. However, in the absence of $\mathrm{N}$ addition, the invasive clonal plants incurred less leaf damage than the native ones when they grew in interspecific competition with each other. This indicates that the leaf herbivores preferred the natives, and suggests that at least some of the herbivores were specialist herbivores on the natives. The difference in leaf herbivory, however, did not translate into a difference in the effect of enemy suppression on the performance of invasive and native clonal plants.

\section{Conclusions}

Our study showed that invasive and native clonal plants in China differed in overall performance, their responses to $\mathrm{N}$ addition and interspecific competition, and in leaf herbivory incurred. With the current data, we cannot say whether these differences reflect pre-adaptations of the invasive clonal species or characteristics that evolved in the introduced range, as this would require studies with plants from the native and introduced ranges of the invasive clonal species. Nevertheless, our results show that already under strongly N-limited conditions, invasive clonal plants in China are competitively superior over native clonal plants, and that invasive clonal plants capitalize more strongly on $\mathrm{N}$ addition. Therefore, ongoing eutrophication is likely to further 
stimulate invasions by alien clonal plants. Furthermore, it will be informative to compare alien clonal plants from their native and introduced ranges, which could help understand whether there exists rapid evolution of clonal traits.

\section{Author contributions}

Y.-J.W. and F.-H.Y. designed the experiment, R.Y. performed the experiment, Y.-J.W., D. C. and F.-H.Y. did the statistical analysis, Y.J.W. and D. C. wrote the first draft of the manuscript, F.-H.Y. and M. v. K. contributed substantially to the revisions.

\section{Acknowledgements}

We thank Ai-Ming Cai, Lie Xu, Jiang-Hua Liu, and Xiao-Hui Yong for help with the experiments. This research was supported by NSFC (31770449, 31570413, 31270465), National Key Research and Development Program of China (2016YFC1201100) and Fundamental Research Funds for the Central Universities (2662015PY130, 2662016PY064).

\section{References}

Adler, P.B., Hillerislambers, J., Levine, J.M., 2007. A niche for neutrality. Ecol. Lett. 10, 95-104.

Aerts, R., Berendse, F., 1988. The effect of increased nutrient availability on vegetation dynamics in wet heathlands. Vegetatio 76, 63-69.

Agrawal, A.A., Kotanen, P.M., 2003. Herbivores and the success of exotic plants: a phylogenetically controlled experiment. Ecol. Lett. 6, 1-14.

Agrawal, A.A., Kotanen, P.M., Mitchell, C.E., Power, A.G., Godsoe, W., Klironomos, J., 2005. Enemy release? An experiment with congeneric plant pairs and diverse aboveand belowground enemies. Ecology 86, 2979-2989.

Alpert, P., Bone, E., Holzapfel, C., 2000. Invasiveness, invasibility, and the role of environmental stress in the spread of nonnative plants. Perspect. Plant Ecol. Evol. Syst. 3, 52-66.

Beckmann, M., Bruelheide, H., Erfmeier, A., 2016. Reduced tolerance to simulated herbivory on clonal organs in alien genotypes: a multi-species experiment with native and introduced origins. Biol. Invasions 18, 549-563.

Bloom, A.J., Chapin, F.S.I., Mooney, H.A., 1985. Resource limitation in plants - an economic analogy. Annu. Rev. Ecol. Syst. 16, 363-392.

Blossey, B., Nötzold, R., 1995. Evolution of increased competitive ability in invasive nonindigenous plants: a hypothesis. J. Ecol. 83, 887-889.

Callaway, R.M., Ridenour, W.M., 2004. Novel weapons: invasive success and the evolution of increased competitive ability. Front. Ecol. Environ. 2, 436-443.

Catford, J.A., Baumgartner, J.B., Vesk, P.A., White, M., Buckley, Y.M., McCarthy, M.A., 2016. Disentangling the four demographic dimensions of species invasiveness. J. Ecol. 104, 1745-1758.

Catford, J.A., Jansson, R., Nilsson, C., 2009. Reducing redundancy in invasion ecology by integrating hypotheses into a single theoretical framework. Divers. Distrib. 15, 22-40.

Chen, D., Ali, A., Lin, C.G., Yong, X.H., Niu, X.H., Cai, A.M., Dong, B.C., Zhou, Z.X., Wang, Y.J., Yu, F.H., 2019. A multi-species comparison of selective placement patterns of ramets in invasive alien and native clonal plants to light, soil nutrient and water heterogeneity. Sci. Total Environ. 657, 1568-1577.

Crandall, R., Knight, T.M., 2015. Positive frequency dependence undermines the success of restoration using historical disturbance regimes. Ecol. Lett. 18, 883-891.

Davis, M.A., Grime, J.P., Thompson, K., 2000. Fluctuating resources in plant communities: a general theory of invasibility. J. Ecol. 88, 528-534.

Dawson, W., Fischer, M., van Kleunen, M., 2012a. Common and rare plant species respond differently to fertilisation and competition, whether they are alien or native. Ecol. Lett. 15, 873-880.

Dawson, W., Rohr, R., van Kleunen, M., Fischer, M., 2012b. Alien plant species with a wider global distribution are better able to capitalize on increased resource availability. New Phytol. 194, 859-867.

Elton, C.S., 1958. The Ecology of Invasions by Animals and Plants. Methuen, London, UK.

Firn, J., Moore, J.L., MacDougall, A.S., Borer, E.T., Seabloom, E.W., HilleRisLambers, J., Harpole, W.S., Cleland, E.E., Brown, C.S., Knops, J.M., Prober, S.M., Pyke, D.A., Farrell, K.A., Bakker, J.D., O'Halloran, L.R., Adler, P.B., Collins, S.L., D’Antonio, C.M., Crawley, M.J., Wolkovich, E.M., La Pierre, K.J., Melbourne, B.A., Hautier, Y., Morgan, J.W., Leakey, A.D., Kay, A., McCulley, R., Davies, K.F., Stevens, C.J., Chu, C.J., Holl, K.D., Klein, J.A., Fay, P.A., Hagenah, N., Kirkman, K.P., Buckley, Y.M., 2011. Abundance of introduced species at home predicts abundance away in herbaceous communities. Ecol. Lett. 14, 274-281.

Funk, J.L., Vitousek, P.M., 2007. Resource-use efficiency and plant invasion in low-resource systems. Nature 446, 1079-1081.

Galloway, J.N., Townsend, A.R., Erisman, J.W., Bekunda, M., Cai, Z., Freney, J.R., Martinelli, L.A., Seitzinger, S.P., Sutton, M.A., 2008. Transformation of the nitrogen cycle: recent trends, questions, and potential solutions. Science 320, 889-892.

Godoy, O., Valladares, F., Castro-Diez, P., 2011. Multispecies comparison reveals that invasive and native plants differ in their traits but not in their plasticity. Funct. Ecol. $25,1248-1259$.

González, A.L., Kominoski, J.S., Danger, M., Ishida, S., Iwai, N., Rubach, A., 2010. Can ecological stoichiometry help explain patterns of biological invasions? Oikos 119, 779-790.

Hautier, Y., Niklaus, P.A., Hector, A., 2009. Competition for light causes plant biodiversity loss after Eutrophication. Science 324, 636-638.

Heard, M.J., Sax, D.F., 2013. Coexistence between native and exotic species is facilitated by asymmetries in competitive ability and susceptibility to herbivores. Ecol. Lett. 16, 206-213.

Heberling, J.M., Fridley, J.D., 2013. Resource-use strategies of native and invasive plants in Eastern North American forests. New Phytol. 200, 523-533.

Huang, Q.Q., Shen, Y.D., Li, X.X., Li, S.L., Fan, Z.W., 2016. Invasive Eupatorium catarium and Ageratum conyzoides benefit more than does a common native plant from nutrient addition in both competitive and non-competitive environments. Ecol. Res. 31, $145-152$.

Keane, R.M., Crawley, M.J., 2002. Exotic plant invasions and the enemy release hypothesis. Trends Ecol. Evol. 17, 164-170.

Kempel, A., Chrobock, T., Fischer, M., Rohr, R.P., van Kleunen, M., 2013. Determinants of plant establishment success in a multispecies introduction experiment with native and alien species. Proc. Natl. Acad. Sci. U.S.A. 110, 12727-12732.

Keser, L.H., Dawson, W., Song, Y.B., Yu, F.H., Fischer, M., Dong, M., van Kleunen, M., 2014. Invasive clonal plant species have a greater root-foraging plasticity than noninvasive ones. Oecologia 174, 1055-1064.

Korell, L., Schmidt, R., Bruelheide, H., Hensen, I., Auge, H., 2016a. Mechanisms driving diversity-productivity relationship differ between exotic and native communities and are affected by gastropod herbivory. Oecologia 180, 1025-1036.

Korell, L., Stein, C., Hensen, I., Bruelheide, H., Suding, K.N.H., Auge, H., 2016b. Stronger effect of gastropods than rodents on seedling establishment, irrespective of native or exotic plant species origin. Oikos 125, 1467-1477.

Kuebbing, S.E., Nuñez, M.A., 2016. Invasive non-native plants have a greater effect on neighbouring natives than other non-natives. Nat. Plants 2, 16134.

Leishman, M.R., Haslehurst, T., Ares, A., Baruch, Z., 2007. Leaf trait relationships of native and invasive plants: community- and global-scale comparisons. New Phytol. $176,635-643$.

Levine, J.M., Adler, P.B., Yelenik, S.G., 2004. A meta-analysis of biotic resistance to exotic invasion. Ecol. Lett. 7, 975-989.

Li, H.L., Ning, L., Alpert, P., Li, J.M., Yu, F.H., 2014. Responses to simulated nitrogen deposition in invasive and native or non-invasive clonal plants in China. Plant Ecol. $215,1483-1492$.

Littschwager, J., Lauerer, M., Blagodatskaya, E., Kuzyakov, Y., 2010. Nitrogen uptake and utilisation as a competition factor between invasive Duchesnea indica and native Fragaria vesca. Plant Soil 331, 105-114.

Liu, J., Dong, M., Miao, S.L., Li, Z.Y., Song, M.H., Wang, R.Q., 2006. Invasive alien plants in China: role of clonality and geographical origin. Biol. Invasions 8, 1461-1470.

Liu, X., Zhang, Y., Han, W., Tang, A., Shen, J., Cui, Z., Vitousek, P., Erisman, J.W., Goulding, K., Christie, P., Fangmeier, A., Zhang, F., 2013. Enhanced nitrogen deposition over China. Nature 494, 459-462.

Liu, Y., Oduor, A.M.O., Zhang, Z., Manea, A., Tooth, I.M., Leishman, M.R., Xu, X., van Kleunen, M., 2017. Do invasive alien plants benefit more from global environmental change than native plants? Glob. Chang. Biol. 23, 3363-3370.

Liu, Y.Y., Sun, Y., Müller-Schärer, H., Yan, R., Zhou, Z.X., Wang, Y.J., Yu, F.H., 2019. Do invasive alien plants differ from non-invasives in dominance and nitrogen uptake in response to variation of abiotic and biotic environments under global anthropogenic change? Sci. Total Environ. 672, 634-642.

Liu, Y., van Kleunen, M., 2017. Responses of common and rare aliens and natives to nutrient availability and fluctuations. J. Ecol. 105, 1111-1122.

Liu, Y., van Kleunen, M., 2019. Nitrogen acquisition of Central European herbaceous plants that differ in their global naturalization success. Funct. Ecol. 33, 566-575.

Lowe, S., Browne, M., Boudjelas, S., de Poorter, M., 2000. 100 Of the World's Worst Invasive Alien Species a Selection From the Global Invasive Species Database. [WWW document]. The Invasive Species Specialist Group (ISSG) a specialist group of the Species Survival Commission (SSC) of the World Conservation Union (IUCN): 12. http://www.issg.org/booklet.pdf.

Ma, J.S., 2014. The Survey Report on Chinese Alien Invasive Plants, Part I \& II. High Education Press, Beijing.

Ma, J.S., Li, H.R., 2018. The Checklist of the Alien Invasive Plants in China. High Education Press, Beijing.

Maron, J.L., Vilà, M., 2001. Do herbivores affect plant invasion? Evidence for the natural enemies and biotic resistance hypotheses. Oikos 95, 363-373.

Müiller, G., Horstmeyer, L., Rönneburg, T., van Kleunen, M., Dawson, W., 2016. Alien and native plant establishment in grassland communities is more strongly affected by disturbance than above- and below-ground enemies. J. Ecol. 104, 1233-1242.

Müller-Schärer, H., Schaffner, U., Steinger, T., 2004. Evolution in invasive plants: implications for biological control. Trends Ecol. Evol. 19, 417-422.

Ordonez, A., Olff, H., 2013. Do alien plant species profit more from high resource supply than natives? A trait-based analysis. Glob. Ecol. Biogeogr. 22, 648-658.

Ordonez, A., Wright, I.J., Olff, H., 2010. Functional differences between native and alien species: a global-scale comparison. Funct. Ecol. 24, 1353-1361. 
Parepa, M., Fischer, M., Bossdorf, O., 2013. Environmental variability promotes plant invasion. Nat. Commun. 4, 1604.

Pinheiro, J., Bates, D., DebRoy, S., Sarkar, D., Core Team, R., 2015. Nlme: Linear and Nonlinear Mixed Effects Models. R Package Version 3.1-119. http://CRAN.R-project. org/package $=$ nlme.

Pyšek, P., Pergl, J., Essl, F., Lenzner, B., Dawson, W., Kreft, H., Weigelt, P., Winter, M., Kartesz, J., Nishino, M., Antonova, L.A., Barcelona, J.F., Cabezas, F.J., Cárdenas, D., Cárdenas-Toro, J., Castaño, N., Chacón, E., Chatelain, C., Dullinger, S., Ebel, A.L., Figureiredo, E., Fuentes, N., Genovesi, P., Groom, Q.J., Henderson, L., Inderjit, Kupriyanov, A., Masciadri, S., Maurel, N., Meerman, J., Morozova, O., Moser, D., Nickrent, D., Nowak, P.M., Pagad, S., Patzelt, A., Pelser, P.B., Seebens, H., Shu, W., Thomas, J., Velayos, M., Weber, E., Wieringa, J., Baptiste, M.P., van Kleunen, M., 2017. Naturalized alien flora of the world: species diversity, taxonomic and phylogenetic patterns, geographic distribution and global hotspots of plant invasion. Preslia 89, 203-274.

Pyšek, P., 1997. Clonality and plant invasions: can a trait make a difference? In: de Kroon, H., van Groenendael, J. (Eds.), Ecology and Evolution of Clonal Plants. Backhuys Publishers, Leiden, pp. 405-427.

Pyšek, P., Richardson, D.M., 2007. Traits associated with invasiveness in alien plants: where do we stand? In: Nentwig, W. (Ed.), Biological Invasions. Springer, Berlin, pp. 97-126.

R Development Core Team, 2012. R: A Language and Environment for Statistical Computing. Available at:. R Foundation for Statistical Computing, Vienna, Austria. http://www.R-project.org.

Rao, L., Allen, E., 2010. Combined effects of precipitation and nitrogen deposition on native and invasive winter annual production in California deserts. Oecologia 162 , 1035-1046.

Richards, C.L., Bossdorf, O., Muth, N.Z., Gurevitch, J., Pigliucci, M., 2006. Jack of all trades, master of some? On the role of phenotypic plasticity in plant invasions. Ecol. Lett. 9, 981-993.

Richardson, D.M., Pyšek, P., Rejmánek, M., Barbour, M.G., Panetta, F.D., West, C.J., 2000. Naturalization and invasion of alien plants: concepts and definitions. Divers. Distrib. 6, 93-107.

Rickey, M.A., Anderson, R.C., 2004. Effects of nitrogen addition on the invasive grass Phragmites australis and a native competitor Spartina pectinata. J. Appl. Ecol. 41, 888-896.

Schlaepfer, D.R., Glättli, M., Fischer, M., van Kleunen, M., 2010. A multi-species experiment in their native range indicates pre-adaptation of invasive alien plant species. New Phyotologist 185, 1087-1099.

Schumacher, E., Kueffer, C., Edwards, P.J., Dietz, H., 2009. Influence of light and nutrient conditions on seedling growth of native and invasive trees in the Seychelles. Biol. Invasions 11, 1941-1954.

Seabloom, E.W., Borer, E.T., Buckley, Y.M., Cleland, E.E., Davies, K.F., Firn, J., Harpole, W.S., Hautier, Y., Lind, E.M., MacDougall, A.S., Orrock, J.L., Prober, S.M., Adler, P.B., Anderson, T.M., Bakker, J.D., Biederman, L.A., Blumenthal, D.M., Brown, C.S., Brudvig, L.A., Cadotte, M., Chu, C., Cottingham, K.L., Crawley, M.J., Damschen, E.I., Dantonio, C.M., DeCrappeo, N.M., Du, G., Fay, P.A., Frater, P., Gruner, D.S., Hagenah, N., Hector, A., Hillebrand, H., Hofmockel, K.S., Humphries, H.C., Jin, V.L., Kay, A., Kirkman, K.P., Klein, J.A., Knops, J.M.H., La Pierre, K.J., Ladwig, L., Lambrinos, J.G., Li, Q., Li, W., Marushia, R., McCulley, R.L., Melbourne, B.A., Mitchell, C.E., Moore, J.L., Morgan, J., Mortensen, B., O'Halloran, L.R., Pyke, D.A., Risch, A.C., Sankaran, M., Schuetz, M., Simonsen, A., Smith, M.D., Stevens, C.J., Sullivan, L., Wolkovich, E., Wragg, P.D., Wright, J., Yang, L., 2015. Plant species' origin predicts dominance and response to nutrient enrichment and herbivores in global grasslands. Nat. Commun. 6, 7710.

Song, M.H., Yu, F.H., 2015. Reduced compensatory effects explain the nitrogen-mediated reduction in stability of an alpine meadow on the Tibetan Plateau. New Phytol. 207, $70-77$.

Song, Y.B., Yu, F.H., Keser, L.H., Dawson, W., Fischer, M., Dong, M., van Kleunen, M., 2013. United we stand, divided we fall: a meta-analysis of experiments on clonal integration and its relationship to invasiveness. Oecologia 171, 317-327.

Strauss, S.Y., Stanton, M.L., Emery, N.C., Bradley, C.A., Carleton, A., Dittrich-Reed, D.R., Ervin, O.A., Gray, L.N., Hamilton, A.M., Rogge, J.H., Harper, S.D., Law, K.C., Pham, V.Q., Putnam, M.E., Roth, T.M., Theil, J.H., Wells, L.M., Yoshizuka, E.M., 2009. Cryptic seedling herbivory by nocturnal introduced generalists impacts survival, performance of native and exotic plants. Ecology 90, 419-429.

van Kleunen, M., Dawson, W., Bossdorf, O., Fischer, M., 2014v. The more the merrier: multi-species experiments in ecology. Basic Appl. Ecol. 15, 1-9.

van Kleunen, M., Dawson, W., Essl, F., Pergl, J., Winter, M., Weber, E., Kreft, H., Weigelt, P., Kartesz, J., Nishino, M., Antonova, L.A., Barcelona, J.F., Cabezas, F.J., Cárdenas, D., Cárdenas-Toro, J., Castaño, N., Chacón, E., Chatelain, C., Ebel, A.L., Figueiredo, E., Fuentes, N., Groom, Q.J., Henderson, L., Inderjit, Kupriyanov, A., Masciadri, S., Meerman, J., Morozova, O., Moser, D., Nickrent, D., Patzelt, A., Pelser, P.B., Baptiste, M.P., Poopath, M., Schulze, M., Seebens, H., Shu, W., Thomas, J., Velayos, M., Wieringa, J.J., Pyšek, P., 2015v. Global exchange and accumulation of non-native plants. Nature 525, 100-103.

van Kleunen, M., Weber, M.E., Fischer, M., 2010v. A meta-analysis of trait differences between invasive and non-invasive plant species. Ecol. Lett. 13, 235-245.

van Mierlo, J.E.M., Wilms, Y.J.C., Berendse, F., 2000v. Effects of soil organic matter and nitrogen supply on competition between Festuca ovina and Deschampsia flexuosa during inland dune succession. Plant Ecol. 148, 51-59.

Vilà, M., Weiner, J., 2004. Are invasive plant species better competitors than native plant species? -evidence from pair-wise experiments. Oikos 105, 229-238.

Wan, F.H., Liu, Q.R., Xie, M., 2012. Biological Invasions: Color Illustrations of Invasive Alien Plants in China. Science Press, Beijing.

Wang, Y.J., Müller-Schärer, H., van Kleunen, M., Cai, A.M., Zhang, P., Yan, R., Dong, B.C., Yu, F.H., 2017. Invasive alien plants benefit more from clonal integration in heterogeneous environments than natives. New Phytol. 216, 1072-1078.

Whitney, K.D., Gabler, C.A., 2008. Rapid evolution in introduced species,' invasive traits' and recipient communities: challenges for predicting invasive potential. Divers. Distrib. 14, 569-580.

Xu, W., Luo, X.S., Pan, Y.P., Zhang, L., Tang, A.H., Shen, J.L., Zhang, Y., Li, K.H., Wu, Q.H., Yang, D.W., Zhang, Y.Y., Xue, J., Li, W.Q., Li, Q.Q., Tang, L., Lu, S.H., Liang, T., Tong, Y.A., Liu, P., Zhang, Q., Xiong, Z.Q., Shi, X.J., Wu, L.H., Shi, W.Q., Tian, K., Zhong, X.H., Shi, K., Tang, Q.Y., Zhang, L.J., Huang, J.L., He, C.E., Kuang, F.H., Zhu, B., Liu, H., Jin, X., Xin, Y.J., Shi, X.K., Du, E.Z., Dore, A.J., Tang, S., Collett, J.L., Goulding, K., Sun, Y.X., Ren, J., Zhang, F.S., Liu, X.J., 2015. Quantifying atmospheric nitrogen deposition through a nationwide monitoring network across China. Atmos. Chem. Phys. 15, 12345-12360.

Zheng, Y.L., Feng, Y.L., Zhang, L.K., Callaway, R.M., Valiente-Banuet, A., Luo, D.Q., Liao, Z.Y., Lei, Y.B., Barclay, G.F., Silva-Pereyra, C., 2015. Integrating novel chemical weapons and evolutionarily increased competitive ability in success of a tropical invader. New Phytol. 205, 1350-1359.

Zuur, A., Ieno, E.N., Walker, N., Saveliev, A.A., Smith, G.M., 2009. Mixed Effects Models and Extensions in Ecology With R. Springer, Berlin. 